\section{The World Health Survey: a report on the field experience in Brazil}

\author{
Pesquisa Mundial de Saúde: \\ relato da experiência de campo no Brasil
}

Luiz Otavio de Azevedo 1

Rita Suely Bacuri Queiroz 2

Carlos Eduardo Menezes de Rezende 3
1 Centro de Informação Científica e Tecnológica, Fundação Oswaldo Cruz, Rio de Janeiro, Brasil.

2 Centro de Pesquisa Leônidas \& Maria Deane, Fundação Oswaldo Cruz, Manaus, Brasil.

3 Faculdade de Medicina de Ribeirão Preto, Universidade de São Paulo, Ribeirão Preto, Brasil.

Correspondence L. O. Azevedo Centro de Informação Científica e Tecnológica Fundação Oswaldo Cruz Av. Brasil 4365,

Rio de Janeiro, $R J$

21945-900, Brasil. azevedo@fiocruz.br

\section{Abstract}

This article reports on the field experience with the World Health Survey in Brazil with the aim of collaborating in the development and enhancement of the methodology and analyzing interview questions based on the interviewers' experience. The authors comment on the field experience and application of the questionnaire, based on reports by regional coordinators and interviewers, in order to shed light on the context in which the interviews took place. The article reports on how the respondents grasped and interpreted the questionnaire. The authors propose improvements in interviewer training and simple interview reporting measures aimed at improved logistics with such nationwide survey instruments.

Survey Methods; Interviews; Questionnaires

\section{Introduction}

The chapter of the World Health Survey (WHS) in Brazil was headed by a group of researchers from the Departamento de Informação em Saúde, Centro de Informação Científica e Tecnológica, Fundação Oswaldo Cruz (Health Information Department, Center for Scientific and Technological Information, Oswaldo Cruz Foundation).

The WHS began in Brazil in January 2003 with a national sample consisting of five thousand randomly selected households in a set of 250 census tracts in 188 municipalities (or counties). Excluded from the sample were the nonurban areas of the North due to difficult access and low population density 1 .

To conduct the WHS, ten local coordinators were selected (responsible for groups of municipalities in the country's five regions), 20 field supervisors, and 50 interviewers affiliated with undergraduate and graduate courses in the health field 2,3.

In addition to the coordinators, supervisors, and interviewers, a study of this size required collaboration by numerous professionals who contributed anonymously to the survey's success. The main challenge was to reach the most distant households, give the health system users a voice, and have all citizens appreciate the importance of their participation in health improvements for the entire Brazilian population. 
The 5,000 interviews were not (and could never have expected to be) even slightly similar, since they were conducted in different regions of the country in order to hear persons living in highly different socioeconomic conditions and with different levels of schooling.

\section{Methodology}

In order to retrieve and portray the field experiences, a research instrument was elaborated with 12 specific questions on the field research experiences, in addition to analyzing questions from the interviewers' own field experience.

The criterion of "ease versus difficulty" was established to identify the following questions: (1) location of addresses (problems with house numbers, difficulties related to low or high-income areas and prejudice or discrimination, weather factors); (2) reactions to informed consent; (3) concerns related to possible consequences of responses; and (4) time devoted to the interview.

The other questions referred to the questionnaire, particularly application of the vignettes and personal reports by the coordinators and interviewers participating in the WHS.

The opportunity to participate in the WHS raised a double challenge for the researchers. First, the task of interviewing or giving voice to the different research subjects with their particular living conditions, and second, the increasing commitment (growing stronger with each municipality or household visited) to not only record the answers within the rigid format of the structured instrument, but to grasp and reflect on the local reality, always more accurate and truthful than the accumulated theoretical knowledge 4 .

The individuals who were kind enough to take time off from their daily routines facilitated the data collection, which was indispensable for the WHS, and the establishment of an important dialogue between their health and life needs and what the political and health systems have offered in terms of their expectations, in addition to the implicit pact established between the interviewers and population, given the numerous requests for their answers to be truly appreciated and taken into account.

The objective was not to systematize all the issues presented by the coordinators and interviewers, but rather to provide some comments and observations in relation to contextual backdrop, which was apparently not captured by the WHS data collection instrument. Based on this objective, the above-mentioned issues were divided into the following topics: Identifying Partners and Learning the Pathway; Receptiveness to the World Health Survey: Proof of Goodwill; Unveiling Scenarios: the Questionnaire as Instrument; and the Path Followed by the Research Teams.

This objective allowed us to elaborate the current study, attempting to give voice to the opinions of interviewers and interviewees concerning the WHS: in the interviewers' case, how their interviews were conducted, as well as their views concerning the interviewees (their health conditions, how they deal with difficulties in obtaining health care, and their very subsistence). We also attempted to capture the interviewees' opinions concerning the importance of their participation in the survey for improving health care and the opportunity to express themselves as national and local citizens.

\section{Results}

Identifying partners and learning the pathway

In order to conduct a survey as large as the WHS in Brazil with five thousand interviews in 250 urban and rural census districts located in 24 States and the Federal District (Brasilia), we knew ahead of time that enormous logistic backup would be needed.

To obtain such support, help was requested from municipal, State, and Federal agencies to ensure the interviewers' access to all the selected households. The field plan indicated that the first contact should be with the Municipal Secretaries of Health to present the proposal and request support. However, in some municipalities the support was obtained from other agencies, including some from outside the health sector, in addition to cases where the mayors themselves spearheaded the proposal.

In Brazil as a whole, the municipal, State, and Federal agencies, either singly or in partnership, provided support for the WHS by ceding employees, accommodations, and vehicles. In some areas the difficulty in locating households was offset by indispensable help from the census-takers, Family Health Program staff, and employees from the Fundação Nacional de Saúde - FUNASA (National Health Foundation) and Ministério do Meio Ambiente (Ministry of the Environment).

On very rare occasions some obstacles were raised to the WHS, but they were soon overcome by fostering a shared understanding of the Survey's objectives. 
Field interviews began in early 2003, coinciding with Brazil's hot rainy season, thus hampering access to rural communities and slowing down the data collection process.

Specifically in relation to identification of households, there were all kinds of situations: addresses that turned out to be empty lots, houses that had caved in and where there was nothing but rubble, and impenetrable dwellings. Thus, each locality showed a unique kind of difficulty: "good water, good people, mud up to your eyebrows. In town, everybody is friendly. In the countryside, on a single day: bus, back of a Toyota, trekking through the mud, motorcycle, horseback, motorcycle (...). Very down-home people, rustic shacks, and the adventure of wading across a creek to do the interviews" (Southeast Brazil). “(...) Often the selected interviewees had to be found at their workplace, namely out in the fields, which literally required that the interviewers climb up hills to hold the interview" (South).

In order to locate the households, each interviewer had a map of the census district and a list of addresses provided by the Instituto Brasileiro de Geografia e Estatística - IBGE (Brazilian Institute of Geography and Statistics). The map and list were generally sufficient to locate the households, but some situations were reported in which assistance from local personnel was indispensable: “(...) the maps were not always accurate as to occupation of the local terrain, since many addresses were nonexistent and/or switched, emphasizing the importance of cooperation by the Family Health Program and National Health Foundation employees" (Central-West).

These reports show how the municipal, State, and Federal agencies, whether singly or in partnership, provided priceless support for conducting the WHS.

\section{Receptiveness to the WHS: proof of goodwill}

“(...) branded people, yeah, happy people...” [excerpt from lyrics by Brazilian singer-composer Zé Ramalho, in the song "Admirável Gado Novo"].

To portray the participants' receptiveness towards the WHS questionnaire, we focused on three aspects: interviewees' opinions about the consequences of the answers; reactions towards informed consent (signing of the data collection document, agreeing to participate in the survey); and reaction towards the duration of the interview.

In a major portion of the medium and large municipalities, especially in the middle and up- per-income urban areas, many interviewees displayed preoccupation and distrust. In general, before the interviews started, people wanted to know exactly what was going to be asked. “(...) When I got there Dona Izaura was already waiting. She was all nervous and asked me right away to explain the survey, because she had read the letter and hadn't understood it. During the interview she got more and more uptight and asked her daughter to get her cigarettes. She chain-smoked during most of the interview, but as we got near the end she calmed down a little and confessed that she had been nervous at the start because she didn't know what it was about, and thought she might lose her retirement pension as a result of the survey" (North).

As expected, residents in households located in low-income areas were more receptive to participating in the WHS, and those from relatively higher-income areas were more reticent.

The reports merely highlight that the residents in poorer areas do not show the same kind of distrust as those living in higher income levels, who tend to feel their privacy invaded. "Because of security issues in the gated communities, we were immediately intercepted by the doormen, and depending on their goodwill we managed to make a few contacts. (...) Even when the introductory letter was left at the reception desk, we were never certain whether it was actually delivered to the residents. This raised a major obstacle, namely the lack of direct contact with someone from the household" (Southeast).

"We were generally well-received at the houses, but there was a persistent sense of insecurity and fear. One female interviewee even pretended she was the maid, because she had recently been robbed by people who claimed to be employees of the public waste disposal company, but when she saw our badges, knapsacks, and caps, she gave her real identity and agreed to participate" (North).

In the smaller municipalities and especially in rural areas, the receptiveness was much quicker. People's concerns were cleared up as the importance of the WHS was explained, ensuring them that the results would not jeopardize the local authorities. Some elderly individuals were afraid to answer the questionnaire, because they thought their replies might put their retirement pensions at risk. People generally expressed caution in exposing their ideas because of the potential consequences of their answers for their lives. “(...) If my name is going to appear in the survey, I won't answer the questions. I don't like having people know my opinions, because this could be a problem when 
I go in to the health clinic for an appointment" (Southeast).

Most of the interviewers found that informed consent was the most delicate moment in the WHS. As one interviewer stated: "In my experience the most difficult part of the work to convince people to participate in the WHS, to answer and sign the questionnaire" (South). The most frequent challenge was the need to sign, particularly in urban areas where people needed long explanations before signing, even when the interviewers ensured them that it was an ethical formality that would not jeopardize them in any way. In such cases, the interviewers needed to make an extra effort to explain the survey's objectives, and in most cases they were successful. There were also situations in which people made a point of participating, but displayed excess distrust, absolutely refusing to sign the consent form.

In the rural areas or counties with up to 100,000 inhabitants, the situation was the opposite, and simply explaining that it was a Ministry of Health survey was sufficient for people to accept it. Even people who had difficulty writing were willing to sign after hearing the interviewers' explanations. For many people, signing the consent form was a sign of how serious the survey was: "This interview is really serious business, because we even have to sign," commented an interviewee (only too happy to participate) in Southeast Brazil.

Participation in the survey was a sign that they have not been totally forgotten by the health authorities. They also made a point of demonstrating their pride in having been selected. The most excited and hopeful people said it was a stroke of good luck.

Although the greatest resistance was due to the fact that people had to give their opinions and then sign, the duration of the interviews was also a particularly critical issue. Varying from an hour and a half to three straight hours, or even beginning one day and ending the next, or beginning in the interviewee's home and ending in the health clinic's waiting room, the WHS was explicit proof of the Brazilian people's goodwill. Since it was a long research instrument, the interview generally began at one speed and ended at another. During the interviews in the State capitals, due to the faster pace of life, we observed some general fatigue, but not to the point of jeopardizing the interviews, rather a level of saturation that people made a point of not concealing. Even in the rural areas or small counties, where most people are more accessible, we also observed some annoyance due to the duration of the inter- views. Even people who had shown their satisfaction in collaborating from the beginning made some negative remarks on how long the interview was taking and were unable to hide how anxious they were to finish. As one interviewer reported, "Sometimes we began the interviews at a table or some room in the house and finished in the kitchen, in the backyard, by the laundry sink, giving one of the children a bath, or having lunch. We made a 'tour' around the house and even to the neighbors" (Southeast).

We should also emphasize the Brazilian people's hospitality, which was decisive for pepping up the interviewers (both male and female), given the difficulties in the field work: “(...) Mr. Guimarães, Mr. Amaral, and Mr. Hugo Martins... names, families, persons, common and unusual places, world views... dignity, humbleness... these people with their life stories, with such sad plots yet still managing to smile, welcoming you into their homes... 'come in, have a seat, make yourself at home!', they serve you what may be the only meat dish of the week... destitute, yet proud ... building their world in the midst of poverty (...)" 3 (p. 7).

The reports reflect the respondents' hospitality, although the majority of the interviewees and interviewers thought the interviews lasted too long; getting the interviewees to sign the informed consent required extra effort and persuasion by the interviewers, and there was concern and distrust among the interviewees that their answers might jeopardize them.

\section{Unveiling scenarios: \\ the questionnaire as instrument}

There were various situations in which the structured WHS questionnaire was incapable of capturing what might have been extremely important events in shaping the health system in terms of planning, financing, or effective responses to health problems 3 .

As for the indicators on household assets and expenses, the questionnaire was embarrassing on consumer items and patterns that are usually present in the middle class, like clothes washers, dishwashers, computers, Internet, and microwaves, in addition to having maids, in addition to expenses with the house upkeep, like gas, water, electricity, and telephones. As reported by a female interviewer from the North, "Ironically, she lives on Rua Bom Jesus, number 3. It might have been number '13' in the hopes that it would attract luck. Her house, or rather her room, is made of plywood, with a packed earth floor, with a single bed and a hammock where her six-month-old daughter is sleep- 
ing. No furniture, stove, or refrigerator, just one bare room. She buys takeout meals... when she can afford to eat. With no running water, she draws her water from the neighbor woman's well, her latrine is at the back of the lot and has no door. I arrived and announced that her household had been selected to participate in the World Health Survey. I explained the survey's goals in detail, and she didn't even flinch. She had been selected to answer the individual questionnaire and I asked her if she was going to participate. She said she was. Always bashful, she would automatically reply 'no! No! No!' to all the questions. Suddenly she looked me in the eye and blurted, 'Lady, are you sure you want me to answer your questions? I don't have any of those things you can mark down in your notebook"'.

When people were asked about their state of health, defined as the relationship between mobility, personal care, pain and ill-being, cognition, social activities, eyesight, sleep, energy, and mood, we noticed that the answers spilled beyond the scales provided in the questionnaire (none, mild, moderate, severe, extremely severe, or very good, good, moderate, bad, very bad), since they indicated two different directions. In one, closer to the biomedical concept, health was linked to physical and symptomatic manifestations. In another, more frequent, health status was associated with social factors. When asked, "How do you rate your current overall health?", in several cases even when the respondents verbalized some health-related problem, they assessed their health as good, since they were still able to work. Taking this same direction were the answers to questions on feelings of sadness, depression, preoccupation, or anxiety in the last 30 days. People frequently reported a low mood, but this was always accompanied by a comment like the following “... but it's not surprising, because I've been out of work... times are hard, right?... you get worried... even lose sleep..." 3 (p. 9).

The concept of skin color (or race), even with a chart furnished by the survey, is still viewed in a relative light, as reported by an interview from the South: "The question on skin color (or race) was quite controversial given that there were cases in which the interviewees - descendents of Italians, with very light complexions looked at the model provided by the survey and pointed to much darker skin. Likewise, when interviewing a Black family, the latter defined themselves as a color close to the white provided in the WHS color chart."

A relevant fact was the amount of medicines Brazilians are exposed to, and they often showed boxes or baskets full of different drugs.
According to one co-author (a physician), dosing regimen errors identified by this part of the survey posed a major ethical dilemma. A question on access to medicines asked whether respondents obtained the prescribed drugs during their last appointments, without referring to the supply by the public or private sector or a prescription that considered the financial limitations of users of a health system which supposedly covers their treatment costs.

The first question in the oral health section asked about dental problems in the previous 12 months. Two situations stood out: persons with obviously poor dental health who denied any dental complaints, and difficulty in accessing dental care.

The questionnaire erred by not asking about preventive activities in the dental area, by concentrating such activities in the "dentist or other oral hygiene specialist". As for tooth loss, the questionnaire worked with extremes: total edentulism or loss of some teeth. In fact, in several cases there were reports of near-total loss of teeth, an answer that was closer to the first option. "Conclusion: Brazil is a toothless country. Young people, 20 years old, without a single tooth in their mouths! Amazing... That's why even this superficial approach to oral health is so important in the survey" (Northeast).

As for the health system's response to expectations and needs, there were some striking characteristics, varying between health needs defined by the dominant biomedical model as compared to the people themselves (in this cases the actual clientele). Even without swerving from the traditional medical care model, this point emphasizes what the questionnaire apparently fails to capture, i.e., doubts as to whether men really did not need care or whether the health services failed to provide what they needed. Men generally received care for injuries, and there was no reference to the health system's response to causal factors, for example by reporting work-related accidents.

Prenatal care was often provided in early pregnancy by the so-called "supplementary system" of services outsourced to the private sector by the public sector, and by the public sector itself in late pregnancy. In addition, although the questionnaire did not investigate this information, respondents reported having medical appointments in private offices, while doing their laboratory tests through the Sistema Único de Saúde - SUS (Unified National Health System).

In the section on quality of care, we observed some discrepancies. Namely, when asked about the health professionals' skills and equipment, 
respondents generally reported them as adequate. However, in most cases these were the only medical skills and equipment they were familiar with, so they had no real basis for comparison. In questions about waiting time, respectful treatment, and clarity of information, what called our attention was the relative nature of any assessment as to waiting time. When there is only one option and the expectation concerns the possibility of receiving versus not receiving care, a lengthy waiting time may be considered reasonable (one of the respondents claimed that four hours was good), while for those with more options, such as a public primary health care unit versus a private health plan, ten or twenty minutes were considered bad. Once again the questionnaire failed to allow this kind of characterization, which could have been captured by evaluating the vignettes 5 , if there had not been a frequent and visible difficulty on the part of the respondents in understanding them and choosing one of the five levels of response (very good, good, moderate, bad, and very bad). In some municipalities, there were frequent reports of illegal conduct involving payment of an extra amount to the public sector in order to obtain access to care, with statements such as "... if you don't pay, they don't treat you...” (Southeast).

In the section on the relationship with the health services and the importance of certain aspects for the clientele (e.g., respect, ease of access, hygiene in the clinics and hospitals, etc.), some answers sounded strange but were subsequently explained by the respondents. Asking about the importance of "contact with the outside world" (being able to receive visits by family and friends, sending messages and receiving information during hospitalization), some people responded with the lowest degree on the scale: not important. This was explained subsequently as the need for rest during hospitalization: “... when you're in the hospital, you have to steer clear of problems..." (Southeast). "Confidentiality of personal information" also failed to appear as important in some interviews, and such answers were justified based on the importance of support from family and friends: "... if you have a problem, the others need to know about it in order to help..." (Southeast).

The research instrument was the object of evaluation in the analyses described above, but for most interviewees it was also an opportunity to let off steam.

"At the end of the interview she said she had really enjoyed it, because she had had the opportunity to say things that she had never revealed to anyone (friends, doctors, or relatives) and had gotten things off her chest with us. This made her feel relieved, as if she had gotten a weight off her back" (North).

"She thanked me for the help, for the interview, and for having listened to her. For a long time she hadn't stopped to talk about herself and to get things off her chest. She felt fine after the interview" (North).

"I was amazed how receptive people were. In most homes, even if people were busy with their housework or in a hurry to leave the house, they took the time to answer all the questions on the questionnaire. My impression is that people were flattered to participate in the survey" (North).

The vignettes portrayed stories about diseases, health problems, and health care 5 . After reading or hearing them, the informants were expected to experience them in their imagination and then indicate what it would be like to experience a given health problem or what their expectations would be in relation to the respective care. There was a striking difficulty in getting people to understand the stories. Suddenly submitted to a test requiring a certain level of abstraction, they either got the answers mixed up or were embarrassed, and answered without understanding the story. Some factors such as limited schooling, an educational model that fails to value abstract thought, and the time constraint with the interviews (the main factor in difficulty with the questionnaire's final vignette) may have accounted for the apparent inadequacy of this part of the questionnaire for some respondents. The scale of answers did not make sense, since there was generally no distinction between severe and extremely severe, good and very good, or bad and very bad: the respondents tended to provide three levels of classification (bad, "so-so", and good).

The vignettes were considered a difficult part of the interview, because in addition to being the last questions, the interviewers noticed how tired the respondents were getting with these questions (very similar and tedious).

The stories in the vignettes booklet failed to capture multidisciplinary health care initiatives, while reinforcing doctor-centered care. Only two other health care fields were mentioned: psychology (in one question) and nursing. The questionnaire portrayed non-medical health professionals in a hierarchically inferior position, and in the case of nurses, depicted embarrassing or compromising situations (showing little attention to the clientele and limited interest in adequate care).

This type of doctor-centered care was echoed during some interviews, when in one of the vi- 
gnettes, where nurses were providing appropriate care to the user of a primary health unit, the interviewee assessed the care as bad because it had not been performed by a doctor 3 .

According to the reports, the structured WHS questionnaire was incapable of capturing the health system's entire configuration, whether in its planning, financing, or actual response to health problems 3 . The vignettes were also considered inadequate by interviewers and interviewees alike, since they were difficult to understand and included questions that were described as monotonous and repetitive.

\section{Discussion}

Strikingly, Brazilians still experience difficulty in viewing quality health care as a citizen's right, viewing it more as a special concession, as expressed by the following remark. Asked if he had waited a long time on line, an interviewee replied: "No, just four hours. It's worse when you don't even get in for treatment". The client appears to presuppose that by their very nature, public health care services involve waiting: "Waiting for hours is alright; what's bad is waiting for days" (Southeast).

Such difficulties were more frequent in small counties, especially in lower-income neighborhoods and rural communities.

In these poorer areas, interviews were almost therapeutic, in the sense of serving as a channel for respondent to list all sorts of problems. Respondents showed the need to have a careful listener for their problems, where the interviewer often played the role of "counselor".

People from low-income areas also had difficulty perceiving their own decision-making role in public policy implementation. They lacked knowledge about the municipal health councils, which could raise future research questions on the quality of society's participation in health policy formulation and social watch.

The interviewers' contact with the interviewees' reality was also an important point, since many interviewers expressed their sadness over their powerlessness in the face of such realities: "From the first town on, various questions have plagued me: how is the Ministry of Health going to give feedback to the people that have been interviewed? Will a letter through the mail find the same people we found in the countryside? Is there a clear difference for all these people between a health plan and a public health program? What are they going to finally do with all these data? What will the outcome be for the participating countries? Being part of this sur- vey has been an incredible human experience for me. There were many surprises and the chance to meet people. Meanwhile, there was my powerlessness in the face of so many life histories and so many health problems" (Minas Gerais).

“(...) The work began, once again revealing people's difficulties, but also their strategies for dealing with social reality. These people have a lot to tell us, even more than we're prepared to hear: Mrs. Maria, 61 years old, illiterate, tells us: 'an illiterate person is blind (...)'”' (São Paulo).

“(...) Mr. João, a garbage-picker, his wife Dona Maria, and their two children have meat, fruit, and vegetables once a week... Dignified, with dignity in adversity... These people are constantly rowing against the current, with their rowboat leaking and their bellies empty, but they keep rowing... I ask Dona Maria, who has diabetes, about some diet prescription: 'poor folks can't go on such a diet'... they row and get sick!" (São Paulo).

\section{Final remarks}

We are left with the perception of a need for progress, to have the municipalities be seen (and see themselves) as units in the Brazilian Federal system and partners with the State and Federal spheres.

Health sector policy reforms in developing countries in recent years, characterized by the neoliberal influence, generally by downsizing state responsibilities and making social policy budget cuts, have made an analysis of National Health Systems indispensable. The World Health Organization (WHO) presented the WHS as a performance evaluation instrument to periodically apply in the 191 member countries. Our attempt has been to use the researchers' field experience with the questionnaire to show that enhancement of the research instrument should consider the questions in a relative light, since an across-the-board, universal reading of the answers can distort or fail to grasp and encompass the real health needs. Social policies, and particularly health policies, by incorporating this type of technology, should be alert to this dimension, aimed at implementing equitable health systems with case-resolving capacity.

The supervisors' and interviewers' reports on the field experience with the WHS spawned suggestions on the following procedures that are already being adopted in the project entitled Development of Baseline Studies in Municipalities Selected for the Program for the Consolidation and Expansion of the Family Health 
Strategy (PROESF), coordinated by Dr. Maria Helena M. de Mendonça (Escola Nacional de Saúde Pública Sergio Arouca, Fundação Oswaldo Cruz - National School of Public Health, Oswaldo Cruz Foundation), currently in the final data collection process in four cities in the State of Rio de Janeiro, which is based on the WHS questionnaire:

(a) The adjustment of the number of questions in the instrument, so that the total interview time does not exceed 60 minutes, if the entire questionnaire is to be applied to a single interviewee, which generally does not occur, thus reducing its duration.

(b) The supervisors should visit the selected interview sites to make the first contact with the potential interviewees and announce the research objectives, do the geo-referencing of the census district, and replace a household whenever necessary. These procedures allow interviewees to know in advance that they will be receiving an interviewer and to welcome them, greatly facilitates signing of the informed consent, and reduces the interview time. Likewise, geo-referencing the sites to be visited, even those that do not appear on the available maps, to be printed and made available to the interviewers by using applications like Google Earth (available at www.google.com.br).

(c) In relation to the field, the lack of a standard record of the interviewers' field experience showed us how important it is to always do a "field questionnaire" based on the instrument used to collect the reports in this study (in other words, a field report roadmap). Many facts are lost because they go unnoticed by the interviewer, while others are recorded that are irrelevant to the theme under investigation. In short, the idea of producing this report is fundamentally important, since it contributes to the evaluation of the methodologies that have been used as well as to the creation of new methodologies.

\section{Resumo}

O objetivo deste trabalho é relatar as experiências de campo da Pesquisa Mundial de Saúde no Brasil com o intuito de colaborar com o desenvolvimento e aprimoramento da metodologia e analisar questões do questionário confrontando-as com a experiência dos entrevistadores. Comentou-se sobre a experiência de campo e a aplicação do questionário aproveitando-se relatos de coordenadores regionais e dos entrevistadores para conhecer o contexto em que transcorreram as entrevistas. Foram relatadas as experiências com relação ao entendimento e compreensão do questionário por parte dos entrevistados. Os autores propõem melhorias na forma de treinamento dos entrevistadores e medidas simples para que elas possam ser relatadas visando o aprimoramento da logística na aplicação de instrumentos desta abrangência territorial.

Métodos de Levantamento; Entrevistas; Questionários

\section{Contributors}

L. O. Azevedo elaborated the questionnaire, analyzed the reports, and drafted the article. R. S. B. Queiroz contributed to the draft and the final review. C. E. M. Rezende collaborated in collecting the reports and drafting the article.

\section{Acknowledgments}

The authors wish to thank the local coordinators (Marcelo Felga de Carvalho, Paulo Germano de Frias, Silvana Granado N. Gama, Giselle C. Gouveia, Sônia Lansky, Maria do Carmo Leal, Karin R. Luhm, Simone Santos, and Mariza M. Theme Filha) for collecting the field experience reports from their teams of interviewers.

\section{References}

1. Vasconcellos MTL, Silva PLN, Szwarcwald CL Sampling design for the World Health Survey in Brazil. Cad Saúde Pública 2005; 21 Suppl:S89-99.

2. Szwarcwald CL, Viacava F, Vasconcellos MTL, Leal MC, Azevedo LO, Queiroz RSB, et al. Pesquisa Mundial de Saúde 2003: o Brasil em números. RADIS 2004; 23:14-33.

3. Rezende CEM, Markman Neto L, Azevedo LO. Pesquisa Mundial de Saúde: relato de uma experiência de campo no Estado de São Paulo. In: Anais do VII Congresso Paulista de Saúde Pública. Ribeirão Preto: Associação Paulista de Saúde Pública; 2003. p. 1-12.

4. Cruz Neto O. O trabalho de campo como descoberta e criação. In: Minayo MCS, editor. Pesquisa social: teoria, método e criatividade. Petrópolis: Editora Vozes; 2002. p. 51-66.

5. Damacena GN, Vasconcellos MTL, Szwarcwald CL. Perception of health state and the use of vignettes to calibrate for socioeconomic status: results of the World Health Survey in Brazil, 2003. Cad Saúde Pública 2005; 21 Suppl:S65-77.

Submitted on 04/May/2005

Final version resubmitted on 29/Aug/2005

Approved on 06/Sep/2005 